NASA/TM-2004-212877

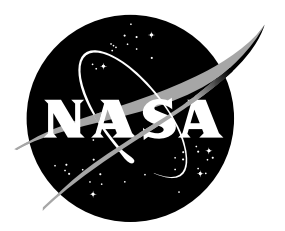

\title{
Mission Steering Profiles of Outer Planetary Orbiters Using Radioisotope Electric Propulsion
}

Douglas Fiehler

QSS Group, Inc., Cleveland, Ohio

Steven Oleson

Glenn Research Center, Cleveland, Ohio 
Since its founding, NASA has been dedicated to the advancement of aeronautics and space science. The NASA Scientific and Technical Information (STI) Program Office plays a key part in helping NASA maintain this important role.

The NASA STI Program Office is operated by Langley Research Center, the Lead Center for NASA's scientific and technical information. The NASA STI Program Office provides access to the NASA STI Database, the largest collection of aeronautical and space science STI in the world. The Program Office is also NASA's institutional mechanism for disseminating the results of its research and development activities. These results are published by NASA in the NASA STI Report Series, which includes the following report types:

- $\quad$ TECHNICAL PUBLICATION. Reports of completed research or a major significant phase of research that present the results of NASA programs and include extensive data or theoretical analysis. Includes compilations of significant scientific and technical data and information deemed to be of continuing reference value. NASA's counterpart of peerreviewed formal professional papers but has less stringent limitations on manuscript length and extent of graphic presentations.

- TECHNICAL MEMORANDUM. Scientific and technical findings that are preliminary or of specialized interest, e.g., quick release reports, working papers, and bibliographies that contain minimal annotation. Does not contain extensive analysis.

- CONTRACTOR REPORT. Scientific and technical findings by NASA-sponsored contractors and grantees.
- CONFERENCE PUBLICATION. Collected papers from scientific and technical conferences, symposia, seminars, or other meetings sponsored or cosponsored by NASA.

- SPECIAL PUBLICATION. Scientific, technical, or historical information from NASA programs, projects, and missions, often concerned with subjects having substantial public interest.

- TECHNICAL TRANSLATION. Englishlanguage translations of foreign scientific and technical material pertinent to NASA's mission.

Specialized services that complement the STI Program Office's diverse offerings include creating custom thesauri, building customized databases, organizing and publishing research results ... even providing videos.

For more information about the NASA STI Program Office, see the following:

- Access the NASA STI Program Home Page at http://www.sti.nasa.gov

- E-mail your question via the Internet to help@sti.nasa.gov

- Fax your question to the NASA Access Help Desk at 301-621-0134

- Telephone the NASA Access Help Desk at 301-621-0390

- Write to:

NASA Access Help Desk

NASA Center for AeroSpace Information 7121 Standard Drive

Hanover, MD 21076 
NASA/TM-2004-212877

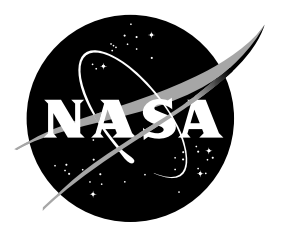

\section{Mission Steering Profiles of Outer Planetary Orbiters Using Radioisotope Electric Propulsion}

Douglas Fiehler

QSS Group, Inc., Cleveland, Ohio

Steven Oleson

Glenn Research Center, Cleveland, Ohio

Prepared for the

Space Technology and Applications International Forum (STAIF-2004) sponsored by the American Institute of Physics

Albuquerque, New Mexico, February 8-12, 2004

National Aeronautics and

Space Administration

Glenn Research Center 


\section{Acknowledgments}

NASA's Project Prometheus, the Nuclear Systems Program, supported the work described within this paper, in whole or part, as part of the program's technology development and evaluation activities. Any opinions expressed are those of the authors and do not necessarily reflect the views of Project Prometheus.

Trade names or manufacturers' names are used in this report for identification only. This usage does not constitute an official endorsement, either expressed or implied, by the National Aeronautics and Space Administration.

Available from

NASA Center for Aerospace Information 7121 Standard Drive

Hanover, MD 21076
National Technical Information Service 5285 Port Royal Road Springfield, VA 22100

Available electronically at http:/ /gltrs.grc.nasa.gov 


\title{
Mission Steering Profiles of Outer Planetary Orbiters Using Radioisotope Electric Propulsion
}

\author{
Douglas Fiehler \\ QSS Group, Inc. \\ Cleveland, Ohio 44135 \\ Steven Oleson \\ National Aeronautics and Space Administration \\ Glenn Research Center \\ Cleveland, Ohio 44135
}

\begin{abstract}
Radioisotope Electric Propulsion (REP) has the potential to enable small spacecraft to orbit outer planetary targets with trip times comparable to flyby missions. The ability to transition from a flyby to an orbiter mission lies in the availability of continuous low power electric propulsion along the entire trajectory. The electric propulsion system's role is to add and remove energy from the spacecraft's trajectory to bring it in and out of a heliocentric hyperbolic escape trajectory for the outermost target bodies. Energy is added and the trajectory is reshaped to rendezvous with the closer-in target bodies. Sample REP trajectories will be presented for missions ranging for distances from Jupiter orbit to the Pluto-Kuiper Belt.
\end{abstract}

\section{BACKGROUND}

Various authors have studied the use of electric propulsion powered by radioisotope power sources for science missions beyond earth orbit (Oleson, 2001a and 2001b, Noble, 1993, 1996, and 1999). A more recent work has shown that such radioisotope electric propulsion (REP) spacecraft can orbit or co-orbit various large and small science targets beyond Mars with transit times comparable to large fission-based nuclear electric propulsion (NEP) vehicles. Although REP vehicles would be much smaller and have less on-board power available for science instruments than fission-based NEP, REP vehicles, like those using NEP, could conduct missions that are not accessible to chemical, solar electric or aerocapture vehicles (Oleson, 2002). This recent work discovered that using a medium class launch vehicle with an upper stage can reduce the REP trip times 50\% from past estimates by using the launch vehicle to provide the Earth escape and acceleration while the REP (generally) only has to decelerate and shape the trajectory to capture at the target.

Besides the outer planets and their moons many other targets of scientific interest exist including the Jupiter Trojans, the Centaurs, other asteroids, comets, and Trans-Neptunian objects (Weissman, 1999) (Figure 1). Exploration of these bodies could address many of the scientific questions posed in the recent National Research Council Decadal Study (National Research Council, 2002).

Recent studies have shown that power and propulsion specific masses of 100 to $150 \mathrm{~kg} / \mathrm{kWe}$ are needed to provide reasonable mission times and performance (Oleson, 2001a, 2001b, 2002, and 2003, Noble, 1993, Noble, 1996, Noble, 1999). Existing radioisotope thermoelectric generators combined with off-the-shelf ion propulsion systems (e.g. the $30 \mathrm{~cm}$ ion propulsion system flown on Deep Space 1 and capable of $500 \mathrm{~W}$ operation) would provide a combined specific mass of almost $300 \mathrm{~kg} / \mathrm{kWe}$. However, advanced radioisotope power systems being developed by NASA could achieve the specific masses of $150 \mathrm{~kg} / \mathrm{kWe}$ or lower required for REP. Ion propulsion with long life that is optimized for efficient operation at low power is also needed to reduce the thruster system mass required for the extended burn times.

The final requirement to make the REP concept feasible is a small but capable spacecraft, with a science package, but not including power and propulsion, of around 100 to $300 \mathrm{~kg}$. While the technologies and a baseline design for such a lightweight REP spacecraft are still under evaluation, the potential New Frontiers Class mission opportunities for such a spacecraft are explored in this work. 


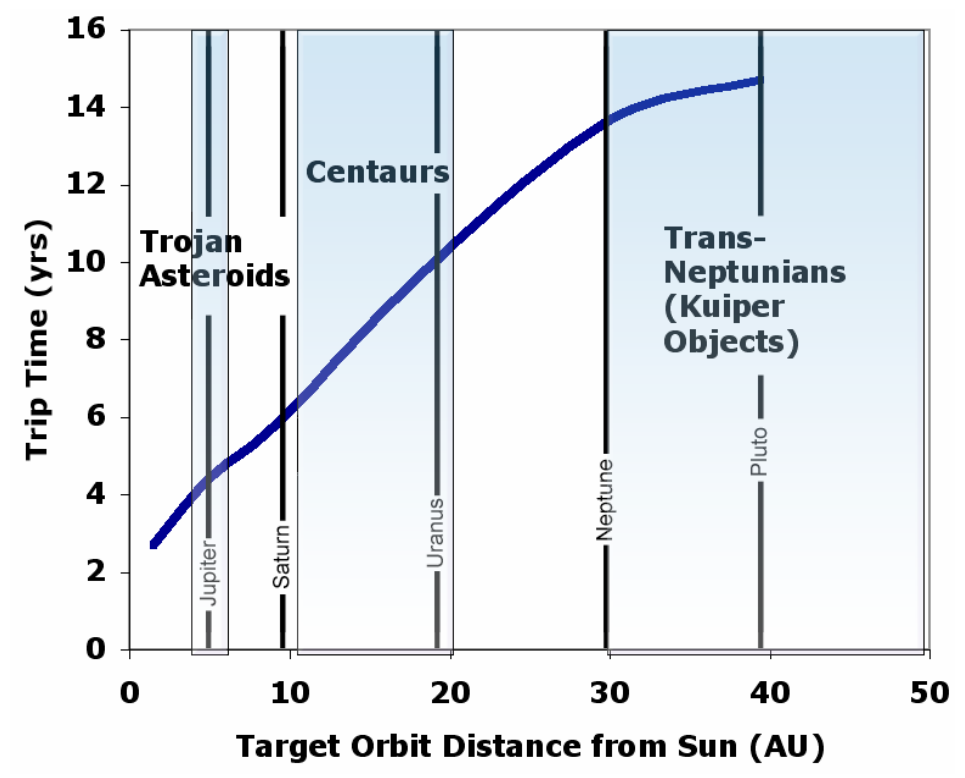

FIGURE 1.-Trip Times to Various Target Bodies Including Planets and Primitive Bodies.

\section{INTRODUCTION}

The three key technologies needed for an REP spacecraft are small, advanced ion thrusters, lightweight radioisotope power systems, and a small spacecraft (total dry mass $<500 \mathrm{~kg}$ ) that can perform valuable science. This scoping study assumed ion thrusters with an operational power range of 100-500 We, Stirling Radioisotope Generators (SRGs) (representative of the advanced systems under development) that can supply constant power of 100-900 We to the ion propulsion system and lightweight spacecraft bus technologies that enable revolutionary $100-300 \mathrm{~kg}$ spacecraft bus designs. See the following references for a complete description of the above technologies (Oleson, 2001a, 2001b, 2002, and 2003).

\section{SYSTEMS ANALYSES}

For the sample outer planetary object missions, the previous technology descriptions were modeled for mass and performance analyses. A launch date of 2011 was chosen to allow sufficient technology advancement, but earlier or later launch dates should have similar results because the distance between Earth and the target bodies is sufficiently large to minimize synodic effects. Trajectories were designed to reach bodies from Jupiter to Pluto, but placement of the spacecraft into final orbits around the target bodies was not considered. Depending on the desired final altitude, the cost to reach the final orbit may be high. The assumed performance of the power and propulsion system is shown in Table 1 . The $750 \mathrm{We}$ power level was chosen based on past mission analysis iteration as near optimal (Oleson, 2002). Using the information in the table, a fixed specific mass (alpha) of $150 \mathrm{~kg} / \mathrm{kWe}$ was assumed for the trajectory runs for this scoping study. The tankage was set to $10 \%$ of the required fuel mass. An additional $30 \%$ contingency, commensurate with mission scoping practices, was assessed to the power and propulsion system. The rest of the spacecraft: Bus, Science and Margin, (BSM) was assumed to have a mass of $267 \mathrm{~kg}$. This BSM includes the contingencies and margins for the bus and science but not the power and propulsion system.

For the ion thruster system, lifetime was assumed possible using advanced grid technologies including thick molybdenum, titanium, or carbon based technologies (pyrolitic graphite) (Haag, 2002). Specific impulse was optimized in the analysis to guide future development. Total propulsion system performance (efficiency) was varied based on required $I_{\mathrm{sp}}$ by the function: Efficiency $=\left(b b * \mathrm{I}_{\mathrm{sp}}{ }^{2}\right) /\left(\mathrm{I}_{\mathrm{sp}}{ }^{2}+\mathrm{dd}^{2}\right)$ where $\mathrm{bb}=0.8358$ and $\mathrm{dd}=$ 2152.99 seconds. This trend is representative of sub-kilowatt thruster test data at similar power levels (Patterson, 1997 and 1998, Foster, 1999, Menart, 1998). Masses for the thrusters and components include gimbals, structure and thermal control masses. A spare PPU was assumed to ensure that two are operational so that the ion thrusters 
can provide roll control during their operation. A Digital Control Interface Unit (DCIU) is added to control the thrusters, PPUs, and the feed system. The DCIU interfaces the propulsion system with the spacecraft computer. The Stirling system technology is based upon nickel-based super alloys and temperatures of 923K.

Shown in Table 1 are the system assumptions for the outer planetary target orbiters. The housekeeping power was limited to $60 \mathrm{We}$ during thrusting. Spacecraft communications were restricted to ion thruster off-times when more power is available. Two-thruster operation is assumed, where possible, to allow for attitude control of the spacecraft during cruise with the ion thrusters. Three thrusters were carried on the spacecraft. Two of the three thrusters are expected to handle the required fuel throughput in case of engine-out. Improvement of thruster lifetime by using advanced materials (such as pyrolitic graphite) and longer life cathodes could reduce the number of thrusters.

TABLE 1.-OUTER PLANET ORBITER SUBSYSTEM ASSUMPTIONS

\begin{tabular}{|c|c|c|}
\hline Component & $\begin{array}{c}\text { Unit } \\
\text { (Mass / Power) } \\
\end{array}$ & $\begin{array}{l}\text { Total }(150 \mathrm{~kg} / \mathrm{kWe}) \\
\text { (Mass / Power) }\end{array}$ \\
\hline Complete SRG System & 19 kg / $162 \mathrm{We}$ (avg.) & $\begin{array}{c}5 \text { Units } \\
94 \mathrm{~kg} / 810 \mathrm{We}\end{array}$ \\
\hline Sub-Kilowatt Ion Propulsion System & & $\begin{array}{l}8 \text { Thrusters, } 3 \text { PPUs } \\
18.1 \mathrm{~kg} / 750 \mathrm{We}\end{array}$ \\
\hline Thruster (with structure, feed and gimbal) & $1.5 \mathrm{~kg}$ & \\
\hline Power Processing Units (PPUs) & $2.1 \mathrm{~kg}$ & \\
\hline Feed System & & $3.1 \mathrm{~kg}$ \\
\hline Digital Control and Interface Unit (DCIU) & $2.5 \mathrm{~kg}$ & \\
\hline Cable (per thruster) & $0.2 \mathrm{~kg}$ & \\
\hline Thermal & $0.4 \mathrm{~kg}$ & \\
\hline Tankage & $10 \%$ & \\
\hline $\begin{array}{l}\text { Net Spacecraft Bus } \\
\text { (Launch Mass Less Science, Power, and Wet Propulsion) }\end{array}$ & & $267 \mathrm{~kg}$ \\
\hline Science & & $50 \mathrm{~kg}$ \\
\hline Required Fuel Throughput per Thruster & 20 to $30 \mathrm{~kg}$ Xenon & \\
\hline Ion Thruster Specific Impulse $\left(\mathrm{I}_{\mathrm{SP}}\right)$ & $\begin{array}{l}\text { Single } \mathrm{I}_{\mathrm{sp}}(2500-3700 \mathrm{sec}) \\
\text { Optimized by trajectory code }\end{array}$ & \\
\hline Estimated Ion Propulsion System Efficiency & $\begin{array}{l}\text { Relative to Optimal } I_{s p} \\
\quad(48 \% \text { to } 62 \%)\end{array}$ & \\
\hline
\end{tabular}

\section{TRAJECTORY DESIGN AND ANALYSIS}

\section{Mission Design Method and Profile}

Trajectory design and optimization was completed using the Direct Trajectory Optimization Method (DTOM) code. As the name suggests, the DTOM is a direct method for obtaining optimal, low-thrust, interplanetary trajectories (Kluever, 1997). The DTOM numerically integrates the three-dimensional equations of motion using modified equinoctial orbital elements to accommodate circular orbits (eccentricity of 0) (Betts, 1994). The parameterized continuous-time control, thrust and coast lengths, launch date scaling factor, and Earth-escape parameters define the generic design space. More specialized problems can be defined with planetary gravity assists, loiter periods at the target body (used for sample-return missions), optimization of power level and specific impulse (either single value or parameterized continuous-time profile), and specialized thruster system models.

A simple mission profile was assumed for these analyses. The launch vehicle assumed was an Atlas V 551 with a Star 48V upper stage and the associated performance obtained from the Atlas Launch System Planner's Guide 
(ILS, 2001). High excess escape energies $\left(C_{3}\right)$, on the order of 145 to $160 \mathrm{~km}^{2} / \mathrm{s}^{2}$, were used to provide most of the energy to propel the spacecraft to the final destination. After a short study optimizing the mission phases, the electric propulsion (EP) thrust profile was determined to be of the form thrust-coast-thrust. The EP system then provided the necessary thrust to modify the ballistic trajectory to meet the end constraints of the mission (i.e. capture at the target planet).

\section{OUTER PLANETARY OBJECT TRAJECTORIES}

\section{Trajectory Characterization}

The REP trajectories to primitive objects or planetary moons of the outer planetary objects can be summarized by performance to distances marked by the outermost planets: Uranus, Neptune, and Pluto. Performance to distances between these outer planet orbits should be similar. REP trajectories for objects at these distances take a similar form (Figures 2 and 3) when optimized for minimum trip time by the DTOM code. The trajectories begin with the launch vehicle providing the initial acceleration to place the spacecraft into the ballistic trajectory seen in Figure 2 $\left(\mathrm{C}_{3}\right.$ on the order of $\left.150 \mathrm{~km}^{2} / \mathrm{s}^{2}\right)$. During the first burn (notated by solid lines in Figures 2 and following), the EP system provides its thrust in such a direction as to place the spacecraft into a hyperbolic heliocentric escape trajectory (energy $>0$ ). This first burn is on the order of 1 to 3 years. At this point, the EP system is able to switch off and allow the spacecraft to coast for another 1 to 3 years (notated by the dotted line in Figures 2 and following). The final burn, on the order of 7 to 9 years, decelerates the spacecraft out of its heliocentric hyperbolic orbit and steers the spacecraft to its rendezvous with the target object.

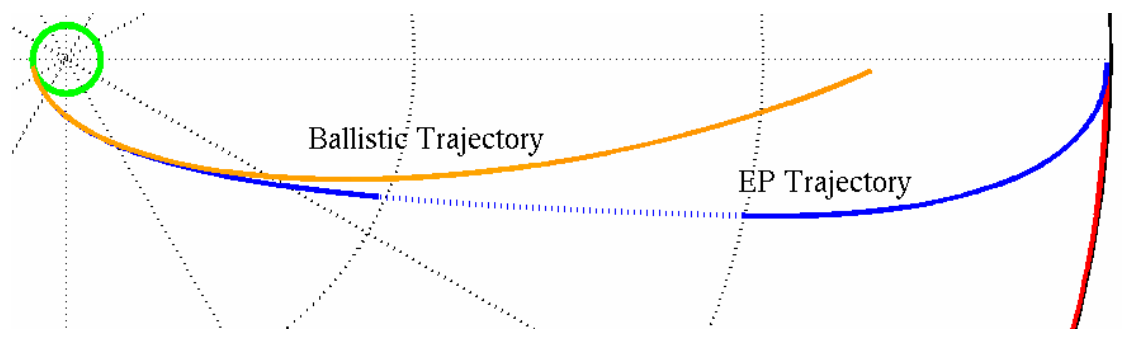

FIGURE 2.-Ballistic Trajectory and EP Trajectory for a Neptune Mission.

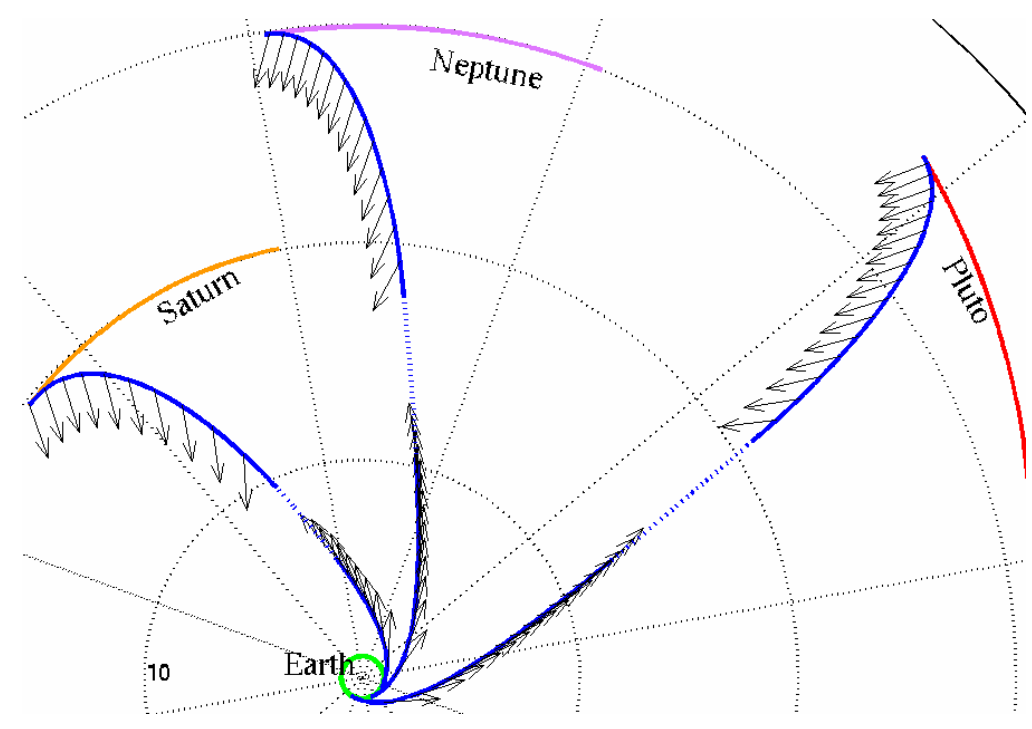

FIGURE 3.-Composite Plot of Uranus, Neptune, and Pluto Trajectories with Thrust Direction Indicated by Arrows. 


\section{REP Trajectory and Steering Profile Analysis}

These trajectories begin with a high- $\mathrm{C}_{3}$ launch from which much of the energy required to travel to the target body is provided. The launch vehicle increases the orbital energy of the spacecraft from that of Earth to almost that of the target body (Figure 4). Equivalently, the launch vehicle provides a boost in velocity over that of Earth, on the order of $12 \mathrm{~km} / \mathrm{s}$ for the Neptune mission (Figure 5).

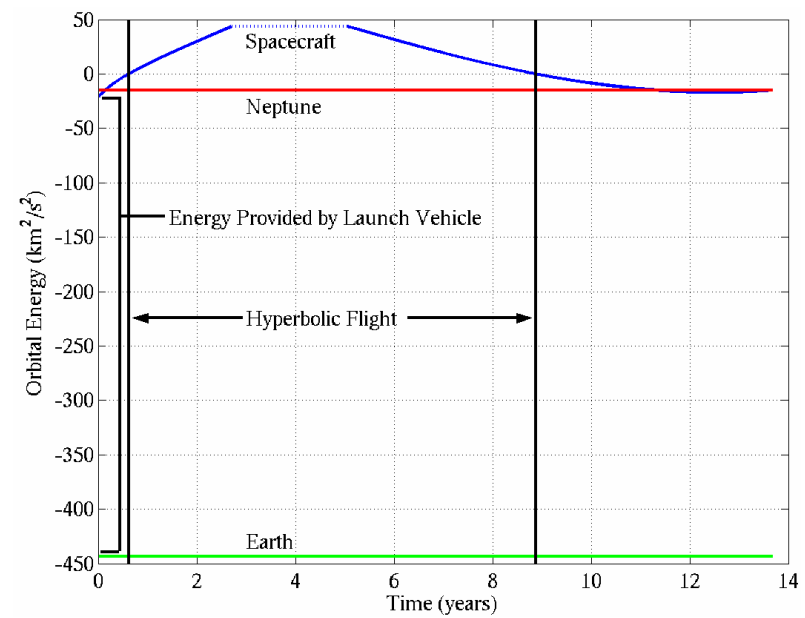

FIGURE 4.-Energy versus Trip Time for the Neptune Trajectory.

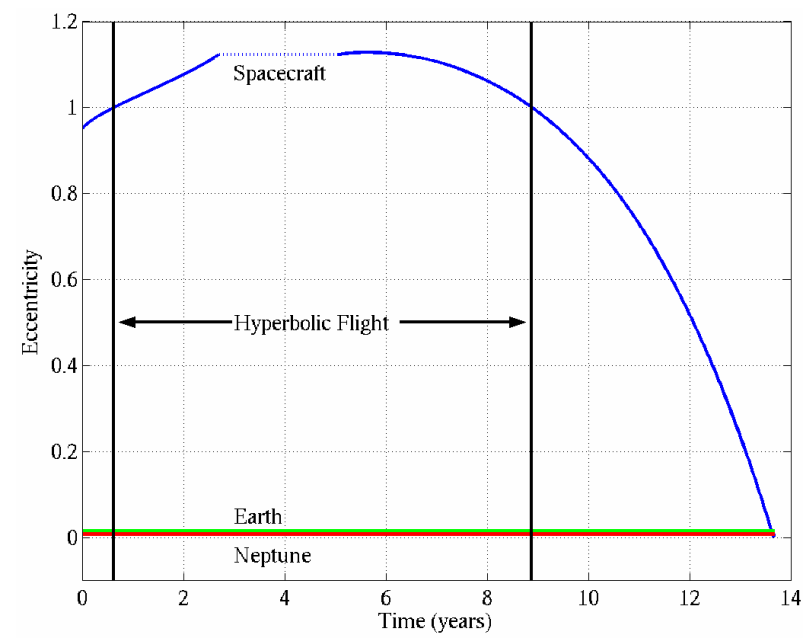

FIGURE 6.-Eccentricity versus Trip Time for the Neptune Trajectory.

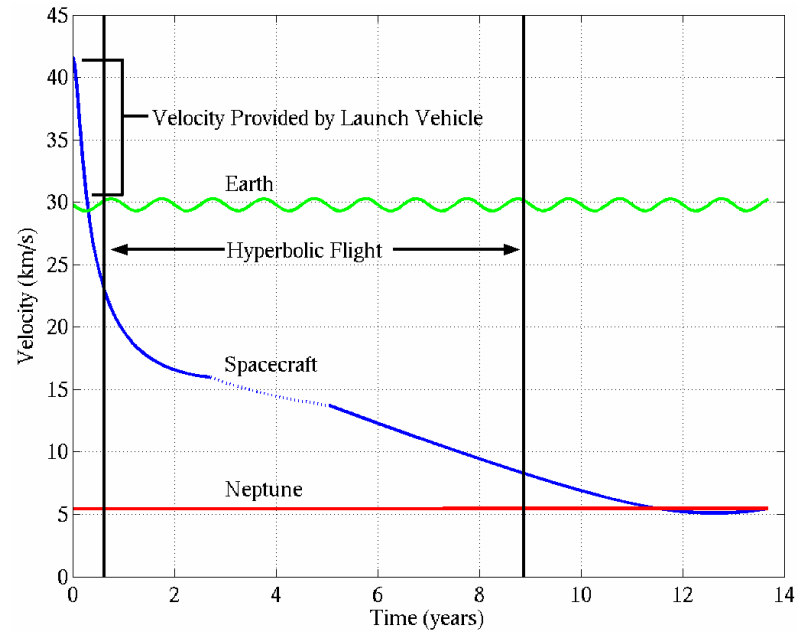

FIGURE 5.-Velocity versus Trip Time for the Neptune Trajectory.

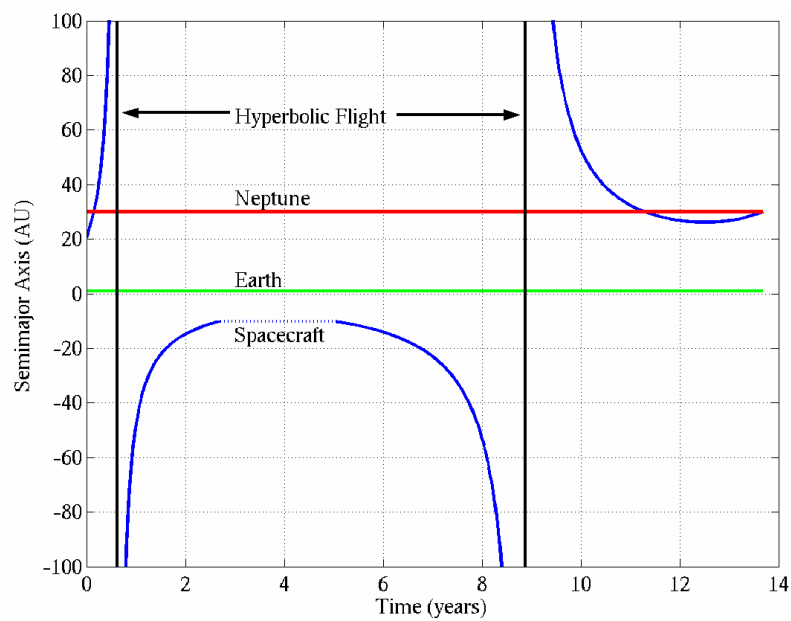

FIGURE 7.-Semimajor Axis versus Trip Time for the Neptune Trajectory.

The main role of the EP system is to bring the spacecraft in and out of the heliocentric hyperbolic escape trajectory. After the high-energy launch, the EP system continues to add energy to the trajectory. Even after the hyperbolic trajectory is achieved (energy $>0$ - Figure 4 , eccentricity $>1$ - Figure 6 , and semimajor axis $<0$ - Figure 7), the EP system continues to add energy to the system in order to minimize the trip time (Figure 4). The hyperbolic phase of the trajectory minimizes the loss of velocity inherent in an elliptical trajectory as the spacecraft travels away from periapsis. The additional thrusting in the hyperbolic phase helps to maintain the velocity of the spacecraft (note the slope of the spacecraft's velocity before and during the hyperbolic phase of the trajectory in Figure 5). The 
spacecraft coasts while on the hyperbolic escape trajectory and then the EP system is turned back on to bring the spacecraft out of the hyperbolic trajectory by reducing the orbital energy of the spacecraft, in a sense, "braking" the spacecraft into its final orbit. Once the heliocentric elliptic trajectory is resumed, the EP system steers the spacecraft into its rendezvous with the target body by reducing the eccentricity (Figure 6) and semimajor axis (Figure 7) of the post-hyperbolic trajectory.

The thrust direction of the trajectories' two burns performs the task of adding or subtracting energy. The first burn, by thrusting in the direction of the velocity vector adds energy and raises aphelion to put the spacecraft into a hyperbolic trajectory. The second burn, removing energy, thrusts mostly against the gravitational pull of the sun to raise perihelion and circularize the trajectory to match the orbit of the target body.

\section{INNER PLANET TRAJECTORIES}

Because of the proximity of the nearer targets (Jupiter and Saturn), the optimal thrust steering profile differs from that of the outer planets (Figure 8). A heliocentric hyperbolic trajectory is never achieved for these trajectories. Neither the Saturn nor the Jupiter trajectories have two burns. Instead, the single burn thrust steering profile for Saturn resembles that of the braking burn for the outer planet cases. The Saturn trajectory's thrust steering profile only must raise the perihelion, because the aphelion raise was completed by the launch vehicle, while adding velocity to match Saturn's velocity for capture. The Jupiter trajectory's thrust steering profile, resembles neither of the burns of the outer planet trajectories but is still a maneuver to raise the perihelion and increase the velocity of the spacecraft's trajectory.

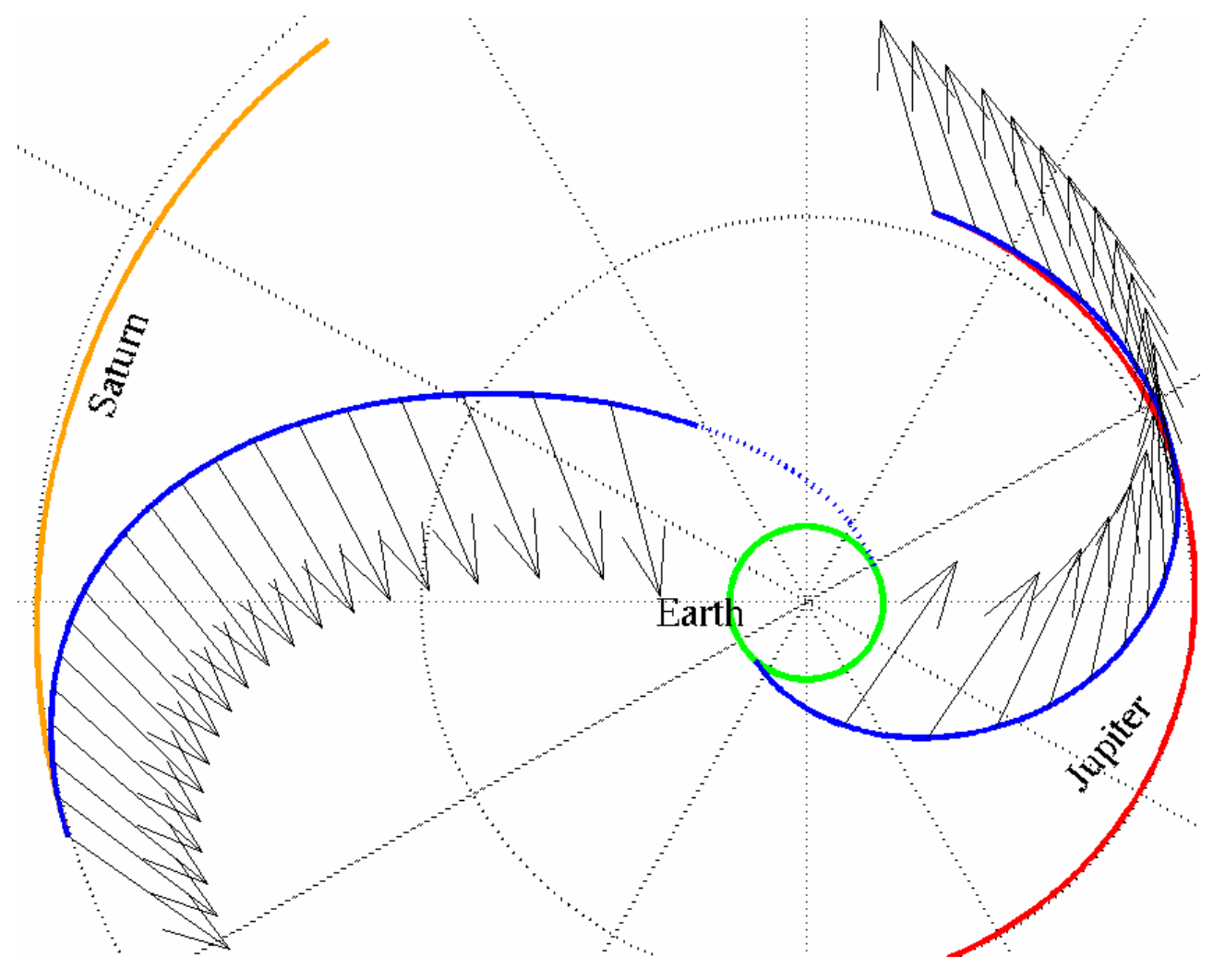

FIGURE 8.-Composite Plot of Jupiter and Saturn Trajectories with Thrust Direction Indicated by Arrows.

As with the trajectories to the outer planets, the trajectories to Jupiter and Saturn have much of the necessary orbital energy provided by the launch vehicle. The remainder of the needed orbital energy is provided by the EP system while steering the spacecraft to the rendezvous. The steering profile for the Jupiter trajectory serves two functions. 
First, it adds the necessary energy (Figure 9), and second, it removes the eccentricity (raises the perihelion) of the trajectory resulting from the launch (Figure 10).

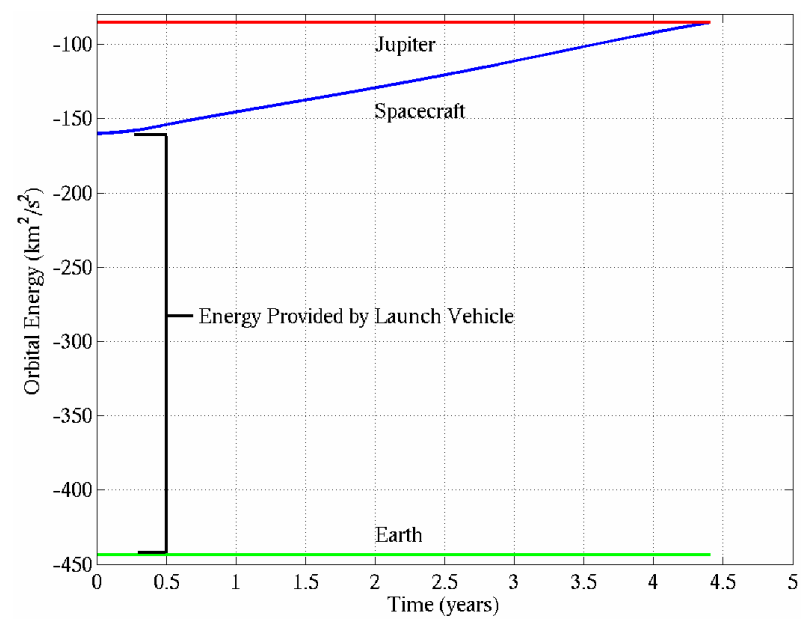

FIGURE 9.- Orbital Energy versus Trip Time for the Jupiter Trajectory.

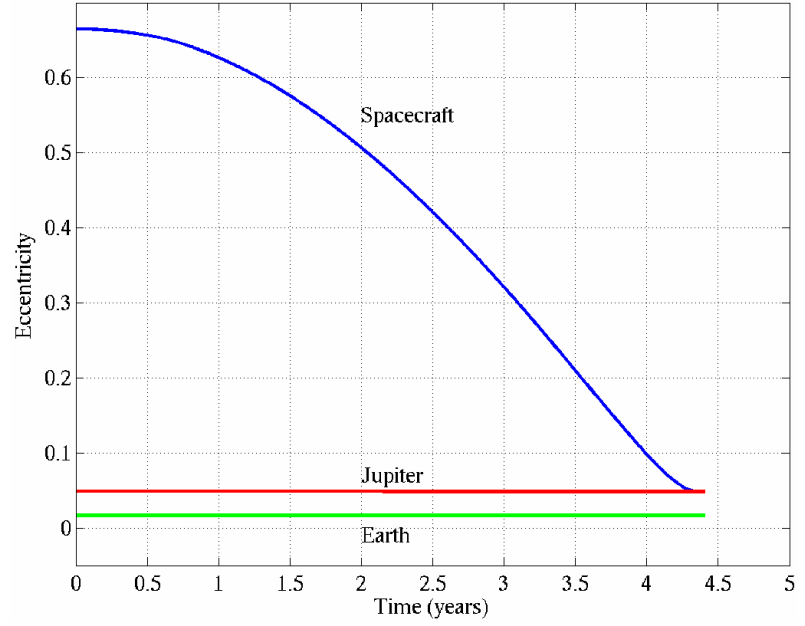

FIGURE 10.-Eccentricity versus Trip Time for the Jupiter Trajectory.

\section{CONCLUSIONS}

All trajectories designed begin with the launch vehicle providing a high excess escape energy launch that provides much of the thrust required for completion of the mission. For missions to the outer solar system (Uranus distances and beyond), the EP system was used to add or remove orbital energy to or from the trajectory, by bringing the spacecraft into or out of a heliocentric hyperbolic escape trajectory. The EP system's role for missions to closer-in bodies (Jupiter and Saturn distances) was to modify the trajectory's perihelion and spacecraft velocity to achieve a rendezvous. This class of trajectories enables small spacecraft utilizing advanced technologies and small science payloads to orbit the outer planets for extended science missions. The missions demonstrated were chosen to show the abilities of REP spacecraft to many target bodies throughout the solar system. This capability is available for missions to intermediate bodies between Jupiter and Pluto as well as to target bodies past Pluto in the Kuiper Belt and beyond.

\section{REFERENCES}

Betts, J.T., "Optimal Interplanetary Orbit Transfers by Direct Transcription,” Journal of the Astronautical Sciences 42, 247-268 (1994).

Foster, J.E. and Patterson, M.J, "Enhanced Discharge Performance in a Ring Cusp Plasma Source," IEPC 99-159, 26th International Electric Propulsion Conference, Kitakyushu, Japan, October 1999, Also NASA/TM-2000-209765.

Haag, T., Soulas, G., "Performance of 8 cm Pyrolytic-graphite Ion Thruster Optics," AIAA-2002-4335, 38th Joint Propulsion Conference, Indianapolis, Indiana, July 2002.

International Launch Systems (ILS), “Atlas Launch System Planner’s Guide,” Rev. 9, September 2001.

Kluever, C.A., "Optimal Low-Thrust Interplanetary Trajectories by Direct Method Techniques," Journal of the Astronautical Sciences 45, 247-262 (1997).

Menart, J.A. and Patterson, M.J., "Magnetic Circuit for Enhanced Discharge Chamber Performance of a Small Ion Thruster," AIAA Paper No. 98-3343, 34th Joint Propulsion Conference, Cleveland, Ohio, July 1998.

National Research Council, New Frontiers in the Solar System: An Integrated Exploration Strategy, National Academies Press, Washington, DC, 2002, Chapter 7.

Noble, R.J., "Radioisotope Electric Propulsion of Small Payloads for Regular Access to Deep Space," AIAA 93-1897, 29th Joint Propulsion Conference, Monterey, California, 1993. 
Noble, R.J., "Radioisotope Electric Propulsion for Small Robotic Space Probes," British Interplanetary Society 49, 455-468, (1996).

Noble, R.J., "Radioisotope Electric Propulsion of Sciencecraft to the Outer Solar System and Near-Interstellar Space," Nuclear News, Nov. 1999, pp 34-40.

Oleson, S.R., Gefert, L., Schreiber, J., McAdams, J., "Sub-Kilowatt Radioisotope Electric Propulsion for Outer Solar System Exploration," Forum on Innovative Approaches to Outer Planetary Exploration 2001-2020, Lunar and Planetary Institute, Houston, Texas, Feb, 2001a.

Oleson, S.R., Gefert, L., Patterson, M., Schreiber, J., Benson, S., McAdams, J., Ostdiek, P., “Outer Planet Exploration with Advanced Radioisotope Electric Propulsion," IEPC-2001-0179, 27th International Electric Propulsion Conference, Pasadena, California, October, 2001b.

Oleson, S.R., Benson, S., Gefert, L., Patterson, M., Schreiber, J., "Radioisotope Electric Propulsion for Fast Outer Planetary Orbiters," AIAA-2002-3967, 38th Joint Propulsion Conference, Indianapolis, Indiana, July, 2002.

Oleson, S.R., Benson, S., Patterson, M., Schreiber, J., Fiehler, D., "Radioisotope Electric Propulsion For New Frontiers Class Missions," IEPC-2001-0137, 28th International Electric Propulsion Conference, Toulouse, France, March, 2003.

Patterson, M.J. and Grisnik, S.P., "Scaling of Ion Thrusters to Low Power," IEPC-97-098, 25th International Electric Propulsion Conference, Cleveland, Ohio, August 1997 Also NASA/TM-1998-206530.

Patterson, M.J., "Low-Power Ion Thruster Development Status," AIAA Paper No. 98-3347, 34th Joint Propulsion Conference, Cleveland, Ohio, July 1998.

Weissman, P., McFadden, L., Johnson, T., Encyclopedia of the Solar System, Academic Press, San Diego, 1999, New Frontiers in the Solar System: An Integrated Exploration Strategy. 


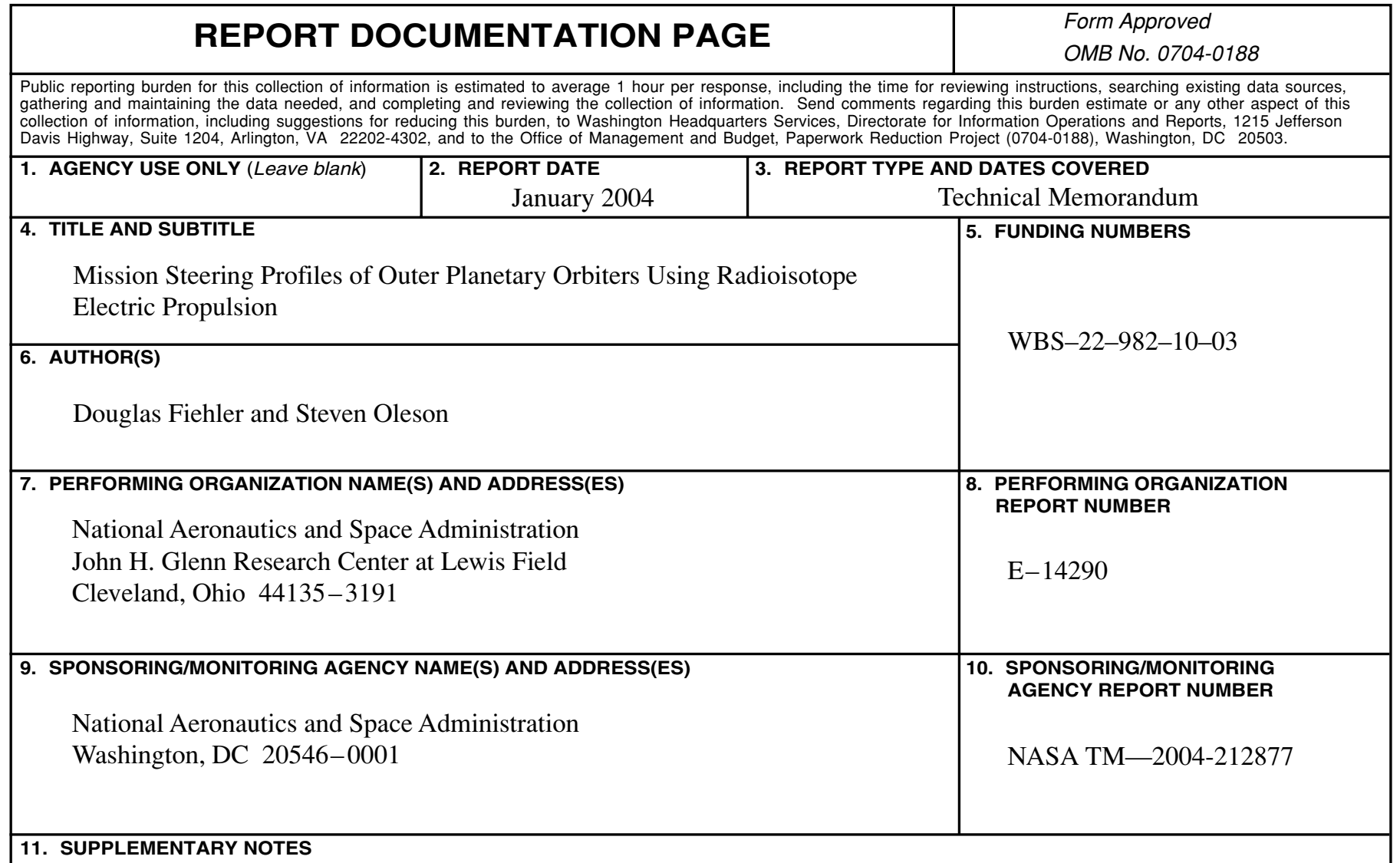

Prepared for the Space Technology and Applications International Forum (STAIF-2004) sponsored by the American Institute of Physics, Albuquerque, New Mexico, February 8-12, 2004. Douglas Fiehler, QSS Group, Inc., Cleveland, Ohio 44135; and Steven Oleson, NASA Glenn Research Center. Responsible person, Douglas Fiehler, organization code 5430, 216-433-2584.

12a. DISTRIBUTION/AVAILABILITY STATEMENT

12b. DISTRIBUTION CODE

Unclassified - Unlimited

Subject Category: 13

Distribution: Nonstandard

Available electronically at http://gltrs.grc.nasa.gov

This publication is available from the NASA Center for AeroSpace Information, 301-621-0390.

13. ABSTRACT (Maximum 200 words)

Radioisotope Electric Propulsion (REP) has the potential to enable small spacecraft to orbit outer planetary targets with trip times comparable to flyby missions. The ability to transition from a flyby to an orbiter mission lies in the availability of continuous low power electric propulsion along the entire trajectory. The electric propulsion system's role is to add and remove energy from the spacecraft's trajectory to bring it in and out of a heliocentric hyperbolic escape trajectory for the outermost target bodies. Energy is added and the trajectory is reshaped to rendezvous with the closer-in target bodies. Sample REP trajectories will be presented for missions ranging for distances from Jupiter orbit to the Pluto-Kuiper Belt.

14. SUBJECT TERMS
Interplanetary trajectories; Trajectory optimization; Trajectory analysis; Space exploration;

Power converters; Space missions; Ion propulsion; Ion engines; Electric propulsion; Stirling cycle;

Trajectories

\begin{tabular}{|c|c|c|}
\hline $\begin{array}{c}\text { 17. SECURITY CLASSIFICATION } \\
\text { OF REPORT } \\
\text { Unclassified }\end{array}$ & $\begin{array}{c}\text { 18. SECURITY CLASSIFICATION } \\
\text { OF THIS PAGE } \\
\text { Unclassified }\end{array}$ & $\begin{array}{c}\text { 19. SECURITY CLASSIFICATION } \\
\text { OF ABSTRACT } \\
\text { Unclassified }\end{array}$ \\
\hline
\end{tabular}

NSN 7540-01-280-5500

Standard Form 298 (Rev. 2-89)

Prescribed by ANSI Std. Z39-18 298-102 